BARBARA JANKOWIAK

Uniwersytet im. Adama Mickiewicza

w Poznaniu

\title{
DOBROSTAN DZIECI WYCHOWYWANYCH PRZEZ KOHABITUJĄCYCH RODZICÓW. \\ CO WYNIKA Z BADAŃ DOTYCZĄCYCH ZNACZENIA STRUKTURY RODZINY DLA ROZWOJU DZIECI?
}

\begin{abstract}
Jankowiak Barbara, Dobrostan dzieci wychowywanych przez kohabitujących rodziców. Co wynika z badań dotyczacych znaczenia struktury rodziny dla rozwoju dzieci? [The Welfare of Children Brought Up by Cohabiting Parents. What Does Research on Family Structure for Children's Development Tell Us?]. Studia Edukacyjne nr 52, 2019, Poznań 2019, pp. 87-96. Adam Mickiewicz University Press. ISSN 1233-6688. DOI: 10.14746/se.2019.52.6
\end{abstract}

Due to the changes in the modern family, many children are brought up in non-traditional families. Cohabitation is one of the alternative forms of the family. The results of the studies on the welfare of children raised in cohabitation relationships are not conclusive, yet the data indicate poorer developmental achievements of these children in comparison with children brought up by married couples are predominant. The article presents the results of research which compares the welfare of children in different forms of relationships and points to three possible reasons for lower developmental achievements of children raised by cohabiting partners. These include: characteristics of the partners, characteristics of the cohabitation relationships and the way of selecting a group for a study which compares the welfare of children in different forms of families, connecting cohabiting partners who are the child's biological parents with those persons forming cohabitation relationships in which only one of the partners is the child's natural parent.

Key words: cohabitation, welfare, children, alternative family forms

\section{Przemiany współczesnej rodziny}

W ostatnich latach zmienia się wizerunek rodziny. Rodzina przestaje być instytucją, a staje się grupą bliskich sobie osób, przestrzenią prywatnych wy- 
borów jednostek, nie podlegających presji społecznych wymogów ${ }^{1}$. Współcześnie zmieniają się sposoby realizacji ról rodzinnych. „Modernizacja współczesnej rodziny wyraża się m.in. w tym, że jej członkowie mogą w twórczy, indywidualny sposób realizować role pełnione w rodzinie" 2 . Poza zmianami ról od lat zmienia się struktura rodziny. Poza małżeństwami powstają nowe formy związków, w których przychodzą na świat i rozwijają się dzieci. Zdaniem Iwony Taranowicz, „w płynnej nowoczesności także rodzina staje się płynna, nie ma stałych, jednoznacznych wzorów porządkujących"3. Jednocześnie, dla prawidłowego rozwoju człowieka, potrzeba stabilności, kontroli i koherencji jest niezwykle istotna, a trwały związek partnerski i rodzina mogą stanowić ważny zasób w radzeniu sobie z wyzwaniami codzienności ${ }^{4}$.

Anna Kwak za alternatywne formy życia rodzinnego uznaje układy wzajemnych powiązań seksualnych i rodzinnych, które nie są usankcjonowane prawnie i/lub nie posiadają biologicznego rodzicielstwa, takie jak:

- związki nie oparte na prawnie zatwierdzonym małżeństwie, np. kohabitacja;

- związki oparte na formalnym małżeństwie, z tym że bez biologicznego rodzicielstwa, np. bezdzietne małżeństwa dobrowolnie rezygnujące z posiadania potomstwa, rodziny rekonstruowane, w których jedno z rodziców nie ma biologicznego związku z dzieckiem;

- związki poprzedzone wcześniejszym małżeństwem, które obecnie zawierają tylko kryterium biologicznego rodzicielstwa, np. rodziny niepełne;

- rodziny nigdy nie oparte na związku małżeńskim, lecz wyłącznie na biologicznym rodzicielstwie, np. niezamężne macierzyństwo.

Z kolei, Krystyna Slany używając pojęcia alternatywne formy życia małżeńsko-rodzinnego, poddaje analizie (poza kohabitacją) takie alternatywne formy życia w społeczeństwie, jak: samotność, monoparentalność, związki homoseksualne ${ }^{5}$.

\section{Kohabitacja jako alternatywna forma życia małżeńsko-rodzinnego}

Według Anny Kwak, kohabitacja może poprzedzać małżeństwo i stanowić okres przedłużonego chodzenia ze sobą, być przygotowaniem do

${ }^{1}$ I. Taranowicz, Role rodzinne w płynnej nowoczesności, [w:] Role rodzinne. Między przystosowaniem a kreacja, red. I. Przybył, A. Żurek, Poznań 2016, s. 30.

2 A. Żurek, Przymus kreowania ról rodzinnych, [w:] Role rodzinne, s. 17.

${ }^{3}$ I. Taranowicz, Role rodzinne w ptynnej nowoczesności, s. 29.

${ }^{4} \mathrm{~K}$. Kuryś-Szyncel, B. Jankowiak, Wspótczesne związki intymne - w poszukiwaniu nowych wzorców relacji, [w:] Role rodzinne. 2002.

${ }^{5}$ K. Slany, Alternatywne formy życia małżeńsko-rodzinnego w ponowoczesnym świecie, Kraków 
małżeństwa, może też stanowić alternatywną wobec małżeństwa formę, zwłaszcza dla osób, które nie zamierzają się pobrać, lub być formą niezamężnego życia, wyrastającą z ideologii niezależności $i^{6}$. W literaturze przedmiotu wyróżnia się więc kohabitację poprzedzającą małżeństwo (premarital cohabitation) ${ }^{7}$, kohabitację typu Living Apart Together (oddzielne mieszkanie mimo tworzenia związku) ${ }^{8}$, a także pomałżeńską kohabitację (postmarital cohabitation), rozpowszechniającą się głównie wśród osób rozwiedzionych, będącą wstępem, jak i alternatywą do powtórnego małżeństwa9 .

W literaturze przedmiotu przeprowadzono wiele badań w celu sprawdzenia wpływu przedmałżeńskiej kohabitacji na jakość i trwałość późniejszych małżeństw. Mimo że dostępne dane nie są jednoznaczne, wiele wskazywało na negatywny wpływ kohabitacji na stabilność późniejszego związku formalnego ${ }^{10}$ oraz że kohabitanci mają wiele cech, które nie sprzyjają jakości i trwałości tworzonych przez nich związków ${ }^{11}$. Czy to oznacza, że kohabitacja jest zawsze związkiem niższej jakości niż małżeństwo?

Helen Bee uważa, że osoby rezygnujące z zamieszkania w związku nieformalnym prezentują bardziej tradycyjne poglądy niż kohabitujący, którzy nie wykazują silnych skłonności do wypełniania tradycyjnych ról płciowych, rzadziej uczestniczą $w$ obrzędach religijnych i rzadziej zgadzają się z tym, że należy wytrwać w małżeństwie bez względu na to, jakie ono jest. To właśnie te cechy decydują o niższej jakości i trwałości tworzonych przez nich związków, a nie sama forma tworzonego związku' ${ }^{12}$.

Także K. Slany powołuje się na badania odnoszące się do cech osób kohabitujących, zgodnie z którymi: mężczyźni są mniej wytrzymali, mniej

${ }^{6}$ A. Kwak, Rodzina i jej przemiany, Warszawa 1994; taże, Rodzina w dobie przemian. Matżeństwo i kohabitacja, Warszawa 2005.

7 C.M. Kamp Dush, C.L. Cohan, P.R. Amato, The Relationship Between Cohabitation and Marital Quality and Stability: Change Across Cohords? Journal of Marriage and Family, 2003, 65, s. 539549; E. Thomson, U. Colella, Cohabitation and Marital Stability: Quality or Commitment? Journal of the Marriage and the Family, 1992, 54, s. 259-267; A. DeMaris, W. MacDonald, Premarital Cohabitation and Marital Instability: A Test of the Unconventionality Hypothesis, Journal of the Marriage and the Family, 1993, 55, s. 399-407.

${ }^{8}$ K. Slany, Alternatywne formy życia matżeńsko-rodzinnego.

9 Z. Wu, Premarital Cohabitation and Postmarital Cohabiting Union Formation, Journal of Family Issues, 1995, 16(2), s. 212-232.

${ }^{10}$ C.M. Kamp Dush, C.L. Cohan, P.R. Amato, The Relationship Between Cohabitation and Marital Quality and Stability: Change Across Cohords? Journal of Marriage and Family, 2003, 65, s. 539549; N.G. Bennett, A.K. Blanc, D.E. Bloom, Link Between Premarital Cohabitation and Subsequent Marital Stability, American Sociological Review, 1988, 53, s. 127-138; A. DeMaris, W. MacDonald, Premarital Cohabitation and Marital Instability, s. 399-407; E. Thomson, U. Colella, Cohabitation and Marital Stability, s. 259-267; J.H. Larson, T.B. Holman, Premarital predictors of marital quality and stability, Family Relations, 1994, 43.

${ }^{11}$ K. Slany, Alternatywne formy życia małżeńsko-rodzinnego.

${ }^{12}$ H. Bee, Psychologia rozwoju człowieka, Poznań 2004. 
pracowici, mniej kompromisowi, ale za to bardziej androgyniczni i postrzegający siebie jako atrakcyjniejszych od mężczyzn żonatych; kobiety są mniej rozważne, bardziej podporządkowane, pracowite, samoakceptujące się, androgyniczne, ekstrawertyczne i mniej dominujące niż kobiety zamężne. Osoby kohabitujące mają także liberalne postawy w stosunku do małżeństwa i rozwodu. Ponadto, częściej kohabitują osoby gorzej wykształcone, biedniejsze, których nie stać na zawarcie małżeństwa ${ }^{13}$. Zdaniem H. Bee, praktyka wspólnego zamieszkiwania przed ślubem jest coraz powszechniejsza w ostatnich pokoleniach, a jej widoczny negatywny wpływ zanika ${ }^{14}$.

Także analiza wyników badań autorki niniejszej rozprawy odnośnie jakości i trwałości związków partnerskich oraz małżeńskich nauczycieli wykazała, że istnieje brak różnic w zakresie jakości i trwałości tworzonych przez nich związków małżeńskich i kohabitacyjnych. Można przypuszczać, że badana grupa nauczycieli jest podobna, jeśli chodzi o postawy życiowe. $Z$ badań tych wynika, że sam wybór kohabitacji jako sposobu na wspólne życie partnerów nie determinuje poziomu jakości i trwałości tworzonego związku ${ }^{15}$.

Kohabitacja może stanowić zarówno alternatywę dla małżeństwa, jak i dla rodziny. Zdaniem Kwak „tak długo, jak w związku nie ma dziecka, można kohabitację traktować jako alternatywę dla małżeństwa, ale w sytuacji pojawienia się dziecka będzie to już alternatywa dla rodziny"16. Zgodnie z danymi Głównego Urzędu Statystycznego (GUS), w Polsce wzrasta liczba urodzeń pozamałżeńskich. Na początku lat 90 . ubiegłego wieku ze związków pozamałżeńskich pochodziło około 6-7\% urodzonych dzieci, w 2000 roku - blisko $12 \%$, zaś w roku 2013 - ponad $23 \%$ dzieci ${ }^{17}$. Rosnący współczynnik dzietności pozamałżeńskiej wynika głównie ze wzrostu liczby rodzin tworzonych przez związki kohabitacyjne ${ }^{18}$.

Istotne dla analizy prowadzonych w kolejnym punkcie badań jest rozróżnienie związków kohabitujących w których wychowywane są dzieci, na związki dwóch kohabitujących rodziców biologicznych i związki tworzone przez jednego kohabitującego rodzica oraz jego partnera/partnerki (związ-

${ }^{13}$ K. Slany, Alternatywne formy życia małżeńsko-rodzinnego.

14 H. Bee, Psychologia rozwoju człowieka.

15 B. Jankowiak, Aktywność seksualna nauczycieli a jakość i trwałość ich związków partnerskich, Poznań 2010.

16 A. Kwak, Rodzina w dobie przemian. Małżeństwo i kohabitacja, Warszawa 2005, s. 92.

17 J. Stańczak, K. Stelmach, M. Urbanowicz, Małżeństwa oraz dzietność w Polsce, Główny Urząd Statystyczny Departament Badań Demograficznych i Rynku Pracy, Warszawa 2016 [online] http://stat.gov.pl/ [2018, kwiecień, 7].

${ }_{18}$ W 2011 r. wśród ludności w wieku 20 lat i więcej około 60\% pozostawało w prawnie zawartych związkach małżeńskich, natomiast ponad $2 \%$ populacji 20 lat+ deklarowało pozostawanie w związkach nieformalnych (kohabitacyjnych); zob: J. Stańczak, K. Stelmach, M. Urbanowicz, Małżeństwa oraz dzietność w Polsce. 
ki kohabitacyjne zrekonstruowane $)^{19}$, bowiem można przypuszczać, że zaangażowanie $\mathrm{w}$ rodzicielstwo $\mathrm{w}$ takich związkach będzie się różnić.

\section{Dobrostan dzieci z rodzin kohabitacyjnych}

Z opisanych trendów wynika, że coraz więcej dzieci żyje w rodzinach kohabitacyjnych. Dlatego, w ostatnich latach uczeni zaczęli badać związek między kohabitacją i dobrostanem dzieci, których wyniki mogą być niezwykle ważne dla pedagogiki jako nauki i pedagogów pracujących z dziećmi i rodzinami ${ }^{20}$. Badania te ogólnie stwierdzają, że dzieci w rodzinach kohabitacyjnych mają gorsze osiągnięcia szkolne ${ }^{21}$ (np. niższą średnią ocen), behawioralnie $^{22}$ (np. większe narażenie na zachowania przestępcze, zachowania agresywne), a nawet zdrowotne ${ }^{23}, \mathrm{w}$ porównaniu z dziećmi z rodzin tworzonych przez małżeństwa. Choć wydawałoby się, że wyniki te są jednoznaczne, Julie E. Artis prowadząc badania porównujące dobrostan dzieci wychowywanych przez małżeństwa $\mathrm{z}$ dwojgiem biologicznych rodziców, małżeństwa zrekonstruowane, związki kohabitacyjne z dwojgiem biologicznych rodziców i związki kohabitacyjne zrekonstruowane, przy zastosowaniu wielowymiarowych modeli kontrolujących cechy dziecka, zasoby gospodarcze rodziny, objawy macierzyńskiej depresji, stabilność i praktyki rodzicielskie, uzyskała wyniki wskazujące na brak zasadniczych różnic między dobrostanem dzieci wychowywanych $w$ różnych typach związków ${ }^{24}$. Powstaje więc pytanie: skąd biorą się tak zasadnicze różnice $\mathrm{w}$ innych wynikach badań?

${ }^{19}$ W.D. Manning, Cohabitation and Child Well-Being, Gender Issues, 2006, 23, 3, s. 21-34.

${ }^{20} \mathrm{~W}$ pracy analizowano artykuły naukowe pozyskane z bazy EBSCO, poprzez wpisanie frazy "cohabitation and children", "family structure and children", wybierając prace, których celem było porównanie wyników rozwojowych dzieci wychowywanych w różnych formach związków.

${ }^{21}$ Dane zebrano z 1999 National Survey of America's Families $(N=35,938)$ żeby sprawdzić znaczenie struktury rodziny dla dobrostanu dzieci. badania porównywały dobrostan dzieci wychowywanych przez małżeństwa z dwojgiem biologicznych rodziców, małżeństwa zrekonstruowane, związki kohabitacyjne z dwojgiem biologicznych rodziców, związki kohabitacyjne zrekonstruowane, samotne matki i samotnych ojców; S.L. Brown, Family structure and child wellbeing: The significance of parental cohabitation, Journal of Marriage and Family, 2004, 66, s. 351-367.

${ }^{22}$ R. Dunifon, L. Kowaleski-Jones, Who's in the house? Race differences in cohabitation, single parenthood, and child development, Child Development, 2002, 73, s. 1249-1264; B.P. Ackerman i in., Family Structure and the Externalizing Behavior of Children From Economically Disadvantaged Families, Journal of Family Psychology, 2001, 15, 2, s. 288-300.

${ }^{23}$ S.K. Kammi, The child health disadvantage of parental cohabitation, Journal of Marriage and Family, 2011, 73(1), s. 181-193.

${ }^{24}$ Dane zebrano od 10 511dzieci przedszkolnych i ich rodziców; J.E. Artis, Maternal Cohabitation and Child Well-Being Among Kindergarten Children, Journal of Marriage and Family, 2007, 69, s. 222-236. 
Okazuje się, że powiązania między kohabitacją a gorszymi rozwojowymi efektami dzieci z tych rodzin, w przyrównaniu do rodzin tworzonych przez małżonków, nie są do końca jasne i jednoznaczne. Być może nie sam wybór kohabitacji jako sposobu na życie z partnerem daje niekorzystny efekt dla dzieci wychowywanych w takich rodzinach, ale mają na to wpływ inne czynniki? W literaturze przedmiotu wskazuje się na trzy możliwe przyczyny: 1) cechy osób tworzących związki kohabitacyjne, które mogą nie sprzyjać pozytywnemu rodzicielstwu; 2) cechy samych związków jako takich, które mogą wiązać się z niekorzystnymi efektami dla dzieci, ale także 3) sposób doboru próby do badań rodzin kohabitujących, który powoduje, że są to zazwyczaj rodziny, w których jeden z rodziców nie jest biologicznym rodzicem dziecka, co daje efekt w postaci mniej zaangażowanego rodzicielstwa i przekłada się na osiągnięcia życiowe dzieci w tej grupie badanej. Te trzy kwestie zostaną poniżej kolejno omówione.

Po pierwsze, efekty selekcji (selection effects) związane z cechami małżonków różnymi od cech kohabitantów mogą stanowić podstawę różnic między środowiskiem rodzinnym tworzonym przez kohabitantów i małżonków ${ }^{25}$. Do cech kohabitantów, które zgodnie z wynikami badań różnią ich od małżonków zaliczano: zdrowie psychiczne matek, wykształcenie partnerów oraz ich zasoby ekonomiczne. Badania wskazują, że kohabitacja występuje częściej wśród osób z niższym wykształceniem i uboższych. Ponieważ instytucja małżeństwa zawiera oczekiwania na temat ról ekonomicznych, partnerzy mogą myśleć, że powinni osiągnąć konkretne cele finansowe, takie jak stałe zatrudnienie lub mieszkanie o określonej jakości, zanim wezmą ślub ${ }^{26}$. Jednocześnie wykazano, że ubóstwo i niski poziom wykształcenia rodziców stanowi czynniki ryzyka dla rozwoju dzieci ${ }^{27}$. Ponadto, dane naukowe wskazują, że kohabitujące matki, w odróżnieniu od mężatek, raportują więcej symptomów depresji ${ }^{28}$, a jak wskazują wyniki badań, depresyjność matki jest jednym z czynników ryzyka rozwoju dzieci i młodzieży ${ }^{29}$.

Po drugie, do najczęściej wymienianych cech związków kohabitacyjnych różniących je od związków małżeńskich należą: zasoby ekonomiczne w ro-

\footnotetext{
${ }^{25}$ Tamże.

${ }^{26}$ J. Seltzer, Families formed outside of marriage, Journal of Marriage and the Family, 2000, 62, s. $1247-1268$.

${ }^{27}$ S.M. Zolkoski, L.M. Bullock, Resilience in children and youth: A review, Children and Youth Services Review, 2012, 34, s. 2295-2303.

${ }^{28}$ J.F. Klausli, M.T. Owen, Stable Maternal Cohabitation, Couple Relationship Quality, and Characteristics of the Home Environment in the Child's First Two Years, Journal of Family Psychology, 2009, 23, 1, s. 103-106.

${ }^{29}$ N.A. Conners-Burrow i in., Low-Level Symptoms of Depression in Mothers of Young Children are Associated with Behavior Problems in Middle Childhood, Maternal \& Child Health Journal, 2016, 20, s. 516-524.
} 
dzinie oraz stabilność rodziny. Związki kohabitacyjne charakteryzowane są zgodnie z częścią wyników badań jako niejednoznaczne i nietrwałe ${ }^{30}$, choć jak wskazują inne badania, różnice w jakości relacji kohabitacyjnych raczej zależą od cech kohabitantów, a nie od cech samej kohabitacji ${ }^{31}$. Ta niejednoznaczność i nietrwałość może tworzyć stres w rodzinie, który z kolei może wpływać na problemy emocjonalne, słabą jakość relacji, niestabilność rodziny i mniej efektywne praktyki rodzicielskie. Te czynniki dają negatywny efekt w rozwoju dziecka ${ }^{32}$.

Trudności ekonomiczne mogą być czynnikiem obciążającym dla dziecka bezpośrednio lub pośrednio. Dzieci w biednych rodzinach mogą nie mieć dostępu do materialnych towarów i usług, które są powiązane z optymalnym rozwojem. Finansowe trudności mogą również wpływać na dobrostan pośrednio, poprzez objawy depresyjne u matki lub niestabilność miejsca zamieszkania. Biorąc pod uwagę różnice w zasobach ekonomicznych między związkami kohabitacyjnymi i małżeńskimi, być może wiele z zaobserwowanych różnic w wynikach rozwojowych dzieci wynika z dochodu rodziców, ich wykształcenia i zatrudnienia matki ${ }^{33}$. Wiele prowadzonych analiz wskazuje, że obserwowane różnice między dziećmi z różnych typów rodzin wynikają z uwarunkowań społeczno-ekonomicznych ${ }^{34}$.

Niestabilność jest wymieniana często jako cecha charakterystyczna kohabitacji. Życie w rodzinie, która doświadczyła wielu zmian, w tym wielu zmian miejsca zamieszkania oraz dodawania nowych i nieznanych osób dorosłych do gospodarstwa domowego może mieć negatywne skutki dla dzieci $^{35}$.

Po trzecie, nie wszystkie dzieci żyjące w rodzinach kohabitacyjnych mieszkają z obojgiem biologicznych rodziców, co nie jest zazwyczaj rozróżniane $\mathrm{w}$ badaniach. Wendy $\mathrm{D}$. Manning powołuje się na dane, z których wynika, że około połowa (54\%) dzieci mieszka w rodzinach kohabitacyjnych, które są strukturalnie podobne do rodzin zrekonstruowanych, ponieważ żyją tylko z jednym biologicznym rodzicem i partnerem tego rodzica ${ }^{36}$. Natomiast, większość badań dotyczących związku kohabitacji z dobrostanem dzieci sku-

${ }^{30}$ S.L. Nock, A comparison of marriages and cohabiting relationships, Journal of Family Issues, 1995,16 , s. 53-76.

31 B. Jankowiak, Aktywność seksualna nauczycieli a jakość i trwałość ich związków partnerskich, Poznań 2010.

${ }^{32}$ J.E. Artis, Maternal Cohabitation and Child Well-Being, s. 222-236.

33 Tamże.

34 W.D. Manning, K.A. Lamb, Adolescent well-being in cohabiting, married, and singleparent families, Journal of Marriage and Family, 2003, 65, s. 876-893.

35 P.R. Amato, Children's adjustment to divorce: Theories, hypotheses, and empirical support, Journal of Marriage and the Family, 1993, 55, s. 23-38.

36 W.D. Manning, Cohabitation and Child Well-Being, Gender Issues, 2006, 23, 3, s. 21-34. 
piało się na rodzinach, $\mathrm{w}$ których rodzic dziecka mieszka z partnerem nie związanym biologicznie z dzieckiem. Prowadzone badania nie rozróżniały więc rodzin kohabitujących z dwojgiem biologicznych rodziców i rodzin kohabitujących z jednym biologicznym rodzicem (zazwyczaj matką) i jej partnerem - czyli rodzin kohabitacyjnych zrekonstruowanych ${ }^{37}$. W związku z tym niewiele wiemy, jak dzieci rozwijają się w rodzinach kohabitacyjnych z dwojgiem biologicznych rodziców ${ }^{38}$. Częściowo te luki w wiedzy naukowej wystąpiły z powodu trudności w uzyskaniu takich danych, a także skupieniu się badaczy na starszych dzieciach i nastolatkach, które częściej żyją w rodzinach kohabitacyjnych zrekonstruowanych.

W ostatnich latach pojawiły się analizy naukowe uwzględniające zarówno stan cywilny rodziców, jak i więzi biologiczne z dziećmi ${ }^{39}$. Biorąc pod uwagę więzi genetyczne między dziećmi i obojgiem rodziców w małżeństwie oraz związku kohabitującyjnym można przypuszczać, że dzieci $\mathrm{z}$ tych rodzin będą miały więcej doświadczeń wspólnych zajęć z rodzicami oraz więcej uczuć, ciepła rodzinnego i zaangażowania rodziców w ich rozwój. Dzieci z rodzin zrekonstruowanych (zarówno kohabitacyjnych, jak i małżeńskich) mają genetyczny związek tylko z jedną osobą dorosłą. Można przypuszczać, że partner rodzica biologicznego będzie mniej skłonny do inwestowania $w$ ich dobrostan niż rodzic biologiczny ${ }^{40}$. Niestety, nadal istnieje niewiele badań dotyczących związku pomiędzy życiem w rodzinie z dwojgiem biologicznych rodziców a dobrostanem ich dzieci, zaś dostępne dane nie są jednoznaczne. Na przykład, cytowane badania J.E. Artis wskazują na brak różnic między dobrostanem dzieci z różnych typów rodzin ${ }^{41}$, natomiast badania S.L. Brown dostarczają wyników świadczących o przewadze dzieci z rodzin małżeńskich nad dziećmi z innych typów rodzin ${ }^{42}$.

Analiza dostępnych danych dotyczących dobrostanu dzieci w różnych formach relacji partnerskich nie dostarcza ostatecznych rozstrzygnięć, $\mathrm{w}$ związku z czym istnieje potrzeba prowadzenia dalszych badań $\mathrm{w}$ tym obszarze. Warto także podkreślić, że analiza znaczenia samej struktury rodziny lub jej zmian dla dobrego rozwoju dzieci i młodzieży może nie być wyczerpująca. Istnieją badania wskazujące, że same zmiany struktury rodziny nie wystarczą, aby przewidywać konsekwencje rozwojowe dla dzieci

${ }^{37}$ S.L. Brown, Family structure and child wellbeing, s. 351-367.

${ }_{38}$ J.E. Artis, Maternal Cohabitation and Child Well-Being, s. 222-236.

${ }^{39}$ S.L. Brown, Family structure and child wellbeing, s. 351-367; J.E. Artis, Maternal Cohabitation and Child Well-Being, s. 222-236.

${ }^{40}$ J.E. Artis, Maternal Cohabitation and Child Well-Being, s. 222-236.

${ }^{41}$ Tamże.

${ }^{42}$ S.L. Brown, Family structure and child wellbeing, s. 351-367. 
i młodzieży ${ }^{43}$. Wydaje się bowiem, że nie tylko forma relacji, ale jej cechy nieformalne wpływają na jakość samego związku ${ }^{44}$, jak również jakość rodzicielstwa w tych związkach.

\section{BIBLIOGRAFIA}

Ackerman B.P., Schoff D’Eramo K., Umylny L., Schultz D., Izard C.E., Family Structure and the Externalizing Behavior of Children From Economically Disadvantaged Families, Journal of Family Psychology, 2001, 15, 2.

Amato P.R., Children's adjustment to divorce: Theories, hypotheses, and empirical support, Journal of Marriage and the Family, 1993, 55.

Artis J.E., Maternal Cohabitation and Child Well-Being Among Kindergarten Children, Journal of Marriage and Family, 2007, 69.

Bee H., Psychologia rozwoju człowieka, Zysk i S-ka Wydawnictwo, Poznań 2004.

Bennett N.G., Blanc A.K., Bloom D.E., Link Between Premarital Cohabitation and Subsequent Marital Stability, American Socjological Review, 1988, 53.

Brown S.L., Family structure and child wellbeing: The significance of parental cohabitation, Journal of Marriage and Family, 2004, 66.

Conners-Burrow N.A., McKelvey L., Perry D., Whiteside-Mansell L., Kraleti S., Mesman G., Holmes K., Kyzer A., Low-Level Symptoms of Depression in Mothers of Young Children are Associated with Behavior Problems in Middle Childhood, Maternal \& Child Health Journal, 2016, 20.

DeMaris A., MacDonald W., Premarital Cohabitation and Marital Instability: A Test of the Unconventionality Hypothesis, Journal of the Marriage and the Family, 1993, 55.

Dunifon R., Kowaleski-Jones L., Who's in the house? Race differences in cohabitation, single parenthood, and child development, Child Development, 2002, 73.

Jankowiak B., Aktywność seksualna nauczycieli a jakość i trwałość ich zwiazków partnerskich, Wydawnictwo Naukowe UAM, Poznań 2010.

Jankowiak B., Kuryś-Szyncel K., Związki intymne jako autorskie projekty życia - próba konceptualizacji ponowoczesnych wzorców relacji, Studia Edukacyjne, 2015, 37.

Kammi S.K., The child health disadvantage of parental cohabitation, Journal of Marriage and Family, 2011, 73(1).

Kamp Dush C.M., Cohan C.L., Amato P.R., The Relationship Between Cohabitation and Marital Quality and Stability: Change Across Cohords? Journal of Marriage and Family, 2003, 65.

Klausli J.F., Owen M.T., Stable Maternal Cohabitation, Couple Relationship Quality, and Characteristics of the Home Environment in the Child's First Two Years, Journal of Family Psychology, 2009, 23, 1.

Kuryś-Szyncel K., Jankowiak B., Wspótczesne związki intymne - w poszukiwaniu nowych wzorców relacji, [w:] Role rodzinne. Między przystosowaniem a kreacją, red. I. Przybył, A. Żurek, Wydawnictwo Naukowe Wydziału Nauk Społecznych UAM, Poznań 2016.

${ }^{43}$ Zob. więcej: G.W. Peterson, K.R. Bush, Families and Adolescent Development, [w:] Handbook of Adolescent Behavioral Problems: Evidence-Based Approaches to Prevention and Treatment, red. T.P. Gullotta, R.W. Plant, M.A. Evans, New York 2015.

${ }^{44}$ K. Kuryś-Szyncel, B. Jankowiak, Wspótczesne związki intymne - w poszukiwaniu; tychże, Zwiazki intymne jako autorskie projekty życia - próba konceptualizacji ponowoczesnych wzorców relacji, Studia Edukacyjne, 37, s. 257-273. 
Kwak A., Rodzina i jej przemiany, Wydawnictwa Uniwersytetu Warszawskiego, Warszawa 1994.

Kwak A., Rodzina w dobie przemian. Małżeństwo i kohabitacja, Wydawnictwo Akademickie Żak, Warszawa 2005.

Larson J.H., Holman T.B., Premarital predictors of marital quality and stability, Family Relations, 1994, 43.

Manning W.D., Cohabitation and Child Well-Being, Gender Issues, 2006, 23, 3.

Manning W.D., Lamb K.A., Adolescent well-being in cohabiting, married, and singleparent families, Journal of Marriage and Family, 2003, 65.

Nock S.L., A comparison of marriages and cohabiting relationships, Journal of Family Issues, $1995,16$.

Peterson G.W., Bush K.R., Families and Adolescent Development, [w:] Handbook of Adolescent Behavioral Problems: Evidence-Based Approaches to Prevention and Treatment, red. T.P. Gullotta, R.W. Plant, M.A. Evans, Springer Science+Business Media, New York 2015.

Seltzer J., Families formed outside of marriage, Journal of Marriage and the Family, 2000, 62.

Slany K., Alternatywne formy życia małżeńsko-rodzinnego w ponowoczesnym świecie, Zakład Wydawniczy Nomos, Kraków 2002.

Stańczak J., Stelmach K., Urbanowicz M., Małżeństwa oraz dzietność w Polsce, Główny Urząd Statystyczny Departament Badań Demograficznych i Rynku Pracy, Warszawa 2016 [online] http://stat.gov.pl/ [2018, kwiecień, 7].

Taranowicz I., Role rodzinne w ptynnej nowoczesności, [w:] Role rodzinne. Między przystosowaniem a kreacja, red. I. Przybył, A. Żurek, Wydawnictwo Naukowe Wydziału Nauk Społecznych UAM, Poznań 2016.

Thomson E., Colella U., Cohabitation and Marital Stability: Quality or Commitment? Journal of the Marriage and the Family, 1992, 54.

Wu Z., Premarital Cohabitation and Postmarital Cohabiting Union Formation, Journal of Family Issues, 1995, 16(2).

Zolkoski S.M., Bullock L.M., Resilience in children and youth: A review, Children and Youth Services Review, 2012, 34.

Żurek A., Przymus kreowania ról rodzinnych, [w:] Role rodzinne. Między przystosowaniem a kreacja, red. I. Przybył, A. Żurek, Wydawnictwo Naukowe Wydziału Nauk Społecznych UAM, Poznań 2016. 